\title{
Simulating faults in a Boeing 737-200 Environmental Control System using a thermodynamic model
}

\author{
Manuel Esperon-Miguez ${ }^{1}$, Ian K. Jennions ${ }^{2}$, Ignacio Camacho Escobar ${ }^{3}$, Nile Hanov ${ }^{4}$ \\ ${ }^{1}$ Johnson Controls International, Sunbury-on-Thames, UK \\ manuel.esperon@jci.com \\ ${ }^{2,3}$ IVHM Centre, Cranfield University, Cranfield, UK \\ i.jennions@cranfield.ac.uk \\ i.camachoescobar@cranfield.ac.uk \\ ${ }^{4}$ Boeing Research \& Technology, St Louis, USA \\ nail.hanov@boeing.com
}

\begin{abstract}
The Environmental Control Systems (ECS), used to provide air to the aircraft cabin at the correct pressure and temperature, is a key driver of maintenance interruptions for military and civil aircraft. Fault detection is particularly difficult, due to the lack of instrumentation and the ability of the ECS's control system to mask symptoms. Understanding how component degradation affects measurable thermodynamic parameters is key to developing a condition monitoring system for an ECS. This work focuses on the development of a thermodynamic model of a Boeing 737-200 ECS capable of simulating faults in three types of component: heat exchangers, valves, and water separators. The thermodynamic model has been validated using data collected on a ground-based instrumented B737-200 ECS. The results show how a thermodynamic model can be used to simulate the change of temperatures and pressures across the ECS when components degrade.
\end{abstract}

\section{INTRODUCTION}

The air supplied into the cabin of a commercial aircraft comes from the Environmental Control System (ECS). This system takes high temperature, pressurized air from the engine or the Auxiliary Power Unit (APU), conditions it with help from Ram air (i.e. outside air) and delivers it into the cabin to keep the passengers at a comfortable temperature, humidity and pressure. The system must be able to deal with a wide range of different external atmospheric conditions and work with the heat and humidity loads generated by passengers.

Thermodynamic models have previously proved successful for preliminary top-level design approaches. (Conceição, et al., 2007) compared the advantages and disadvantages of having a 3 or 4 wheel Air Cycle Machine (ACM) as part of an ECS via the use of a thermodynamic model. (Scott \& Davis, 1976) and (Junior, et al., 2009) make use of the coefficient of performance (COP) to analyse the contribution of the main thermodynamic parameters, such as compressor and turbine efficiencies or heat exchanger effectiveness, in the global performance of the ECS during a typical flight. Thermodynamic analysis has also proved useful when effects of humidity need to be studied, as is shown by (Childs, et al., 2016). Moreover, the system level performance of the components of an ECS can be inferred from a thermodynamic optimization, since the global performance of the system is affected by the thermodynamic irreversibility present in the actual system processes, as shown by (Pérez Grande \& Leo, 2002) and (Vargas \& Bejan, 2001). This means that the optimal arrangement of components can be obtained by means of minimizing the entropy generation of the global system. However, there is a lack of accurate thermodynamic models validated against real data that take into account humidity variations through the ECS.

In terms of ECS modelling and simulation techniques, two main trends can be distinguished. On the one hand, there are examples of 1D models (i.e. thermodynamic models or models that do not consider geometry), either for steady or dynamic simulations, developed using different software platforms, such as FLECS (Functional Model Library of the ECS) in Matlab (Scholz, et al., 2007), EASY5 in FORTRAN (Burroughs \& Hammond, 1983), Flowmaster (Tu \& Lin, 2011) or Modelica (Jordan \& Schmitz, 2014). Regardless of the platform employed, most of these models are used to support top-level design activities since they provide insight into ECS performance at a system level. On the other hand, there are examples of 3D models which focus on specific components (Chen, et al., 2015) where a Wall-Film Splashing model of a High Pressure Water Separator (HPWS) has been developed using Ansys-Fluent. Since this latter approach leads to a more detailed study about fluid and flow properties, coupling both methods provides a powerful combination (Chen, et al., 2015). 
The ECS is considered one of the major schedule interrupt drivers for many airline operators. However, it is uncommon for the ECS to present symptoms that can be noticed by the passengers or the crew because the control system can compensate for even severe levels of degradation and still maintain the desired cabin temperature. Since there is very limited instrumentation on an ECS, repairs can only be carried out once the level of degradation of ECS components becomes extremely severe, i.e. a fault has occurred. Thus, being able to detect and isolate faults in an ECS, as well as to assess components health status, is a priority.

The aim of this project was to be able to model the behaviour of a 737-200 ECS under healthy and faulty conditions with different levels of degradation for each of its components. The model has to be able to simulate how temperature, pressure, and humidity change at the inlet/outlet of each component.

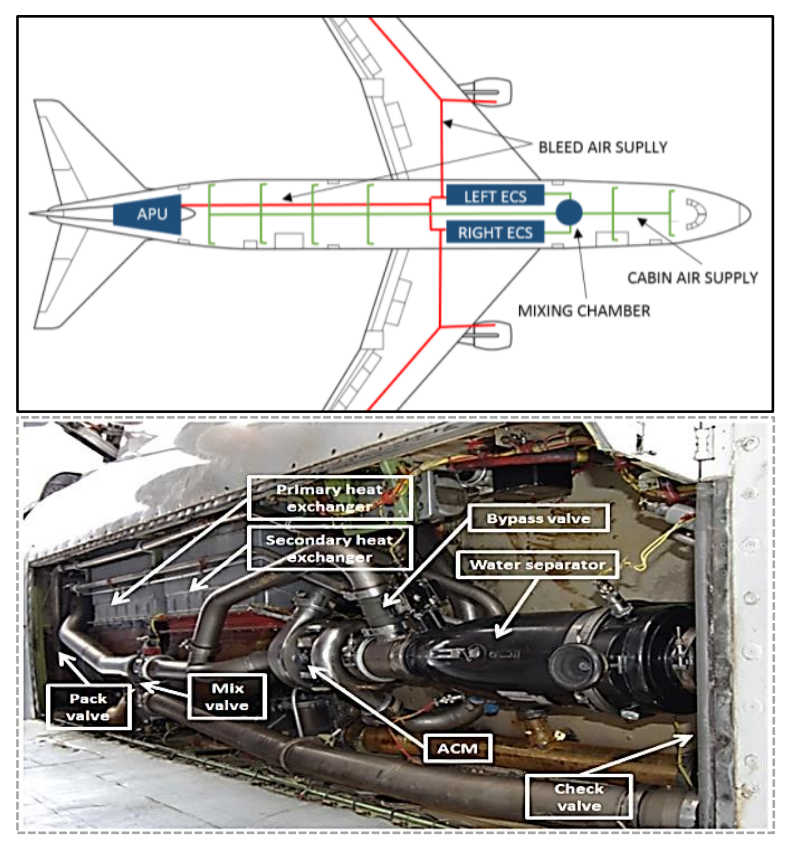

Figure 1 Example of cabin air supply architecture on a civil aircraft (top) and picture of a Boeing 737-200 ECS (bottom).

\section{SYSTEM DESCRIPTION}

The ECS supplies pressurised air to regulate cabin temperature, pressure, and humidity. Fresh compressed air is provided to the ECS by either the engines or the Auxiliary Power Unit (APU) through the Bleed Air System (BAS) (Figure 1). The ECS reduces the temperature and pressure of the bleed air supply to those suitable for the crew and passengers. Excess heat is extracted using ram air. The Boeing 737-200 has two ECS units located at the bottom of the aircraft.

The 737-200 ECS uses a reverse Brayton cycle (Figure 2) in which hot pressurized air from the BAS enters the ECS through the pack valve (1). This butterfly valve ensures the mass flow in the ECS remains constant. Then, air is cooled by the primary heat exchanger (1-2) using ram air (9-10). Afterwards air enters the Air Cycle Machine (ACM) where a compressor (2-3) increases its pressure and temperature. The air is then cooled again using ram air (9-11) in the secondary heat exchanger (3-4). As the air re-enters the ACM it gets expanded in the turbine (4-5) reducing its temperature and pressure and generating mechanical power to drive the compressor. The outlet temperature of the turbine can drop below saturation point and cause condensation. To prevent liquid water from reaching the cabin the 737-200 ECS uses a Water Separator (WS) (6-7) with a coalescer bag to reduce moisture. In some cases, the outlet temperature of the turbine (5) can fall below freezing point resulting in a build-up of ice, which could block the ECS. A temperature switch can send a signal to open the bypass valve to inject hot air into the turbine outlet (5). In order to regulate the temperature of the air supplied to the cabin (8) the cold stream coming from the water separator (7) is mixed with hot air that comes directly from the pack valve (1). The mix valve regulates the proportion of cold and hot flows using two valves connected by a common shaft so when one is fully open the other is closed.

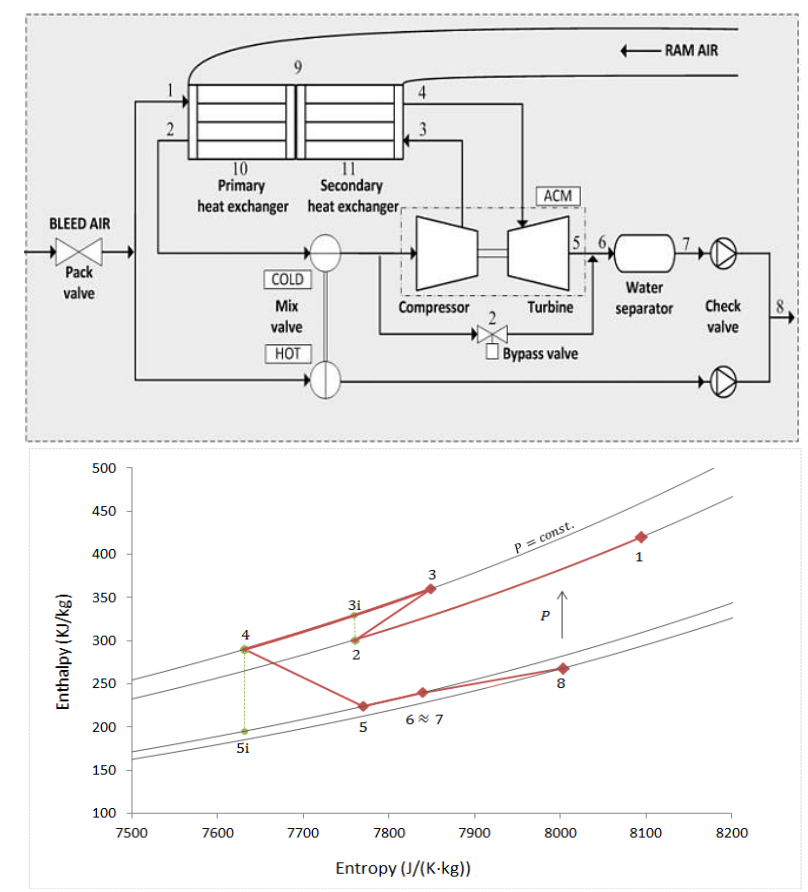

Figure 2 Boeing 737-200 ECS schematic (top) with each point represented in the h-s diagram of its reverse Brayton cycle (bottom)

\section{Methodology}

Data for this project had been collected by a Boeing team in collaboration with Southern Illinois University (SIU) by instrumenting a 727-200 ECS to measure pressures, 
temperatures, and valve positions. Tests were first run in healthy conditions, after which a series of faults were injected in different components with multiple levels of severity.

Access to detailed engineering data (e.g. component geometry or material characteristics) was not possible. Consequently, the research team decided to model the ECS using a 1D thermodynamic model. Thermodynamic models present the advantage of being capable of accounting for deviations between actual and ideal processes, which is particularly useful when modelling component degradation and the impact it has at a system level.

Some model parameters are mass flow dependent (e.g. heat exchanger effectiveness or turbine pressure ratios) but mass flows were not measured during the experiments. Consequently, the model uses empirical equations in certain parts to simulate the effect of changes in valve position.

With all these factors under consideration, the methodology employed to develop the model was:

1. Identify which ECS faults had the biggest impact on maintenance organizations and run tests on the ground based Boeing 737-200 injecting these faults.

2. Develop a thermodynamic model of the ECS which includes empirical equations to account for the effect of valve position changes on thermodynamic parameters.

3. Calibrate the ECS thermodynamic model using data representative of a healthy ECS, by adjusting the parameters of the empirical equations.

4. Validate the ECS thermodynamic model to determine its accuracy. The validation uses two datasets: data collected from a healthy ECS (this is a different dataset to the one used for calibration) and data collected during the fault injection experiments.

\section{EXPERIMENTS}

The experiments were conducted on a ground-based Boeing 737-200 (Figure 3) running one of the two identical ECSs and using the right engine at full throttle as a source of bleed air. The cabin doors remained closed during the tests and the ram air intake was open.

Using the engine to run the ECS provided a higher mass flow of bleed air and inlet pressure than what could be provided with the APU and it also allowed for a better control of the testing conditions (while the engine speed could be controlled with the throttle, the APU in this aircraft is either on or off). Therefore the team decided to focus on gathering data using the right engine.

The B737-200 ECS has two onboard temperature sensors: a RAM air temperature sensor which is used to regulate the RAM mass flow via the RAM inlet flap; and a temperature sensor located in the aft of the water extractor discharge used to regulate the PACK outlet temperature. The ECS does not have any onboard pressure. Consequently, the ECS cannot capture enough data to validate the model in real flight conditions.

Given the characteristics of the instrumentation fitted to the ECS for these experiments, the data could only be gathered in ground runs. However, the inlet conditions are regulated by the engine bleed air system and the pack valve, providing the same pressure, temperature, and mass flow as in flight conditions. While the RAM temperature and massflow will differ, the model equations capture the deviation in external conditions and therefore the model can be used in flight conditions.

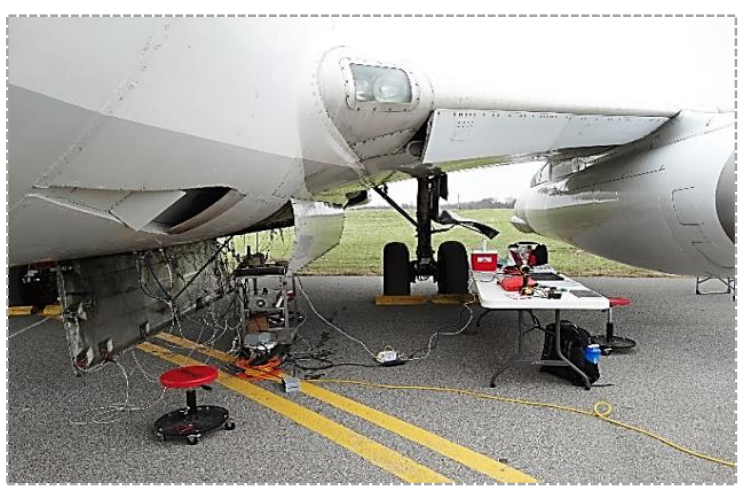

Figure 3 Instrumentation run-out from the Aircraft

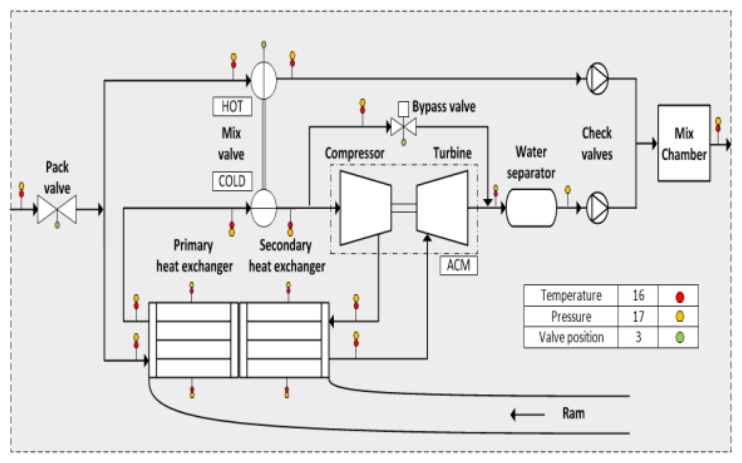

Figure 4 Schematic of ECS Sensor Layout

\subsection{Instrumentation}

The instrumentation consisted of a total of 36 sensors to measure temperatures, pressures, and valve positions. The locations for each sensor are shown in Figure 4. Temperature was measured using Type-K thermocouples inserted directly into the air stream through $5 \mathrm{~mm}$ holes drilled into the ECS titanium pipes and secured in place with clamps that went around the chosen point. Pressure measurements were collected using two types of pressure sensors: 100 psi pressure sensors in the high pressure zone (upstream of the turbine), and 10 psi pressure sensors in the low pressure zone (downstream of the turbine). The position of the pack valve and the bypass valve were measured using potentiometers. All the sensors were connected to a Yokogawa MX100 Data Acquisition Unit configured to collect data at $10 \mathrm{~Hz}$, which 
was considered sufficient to capture the system's behaviour in steady state conditions.

\subsection{Tests in healthy conditions}

The aim of tests in healthy conditions was to collect data to characterise the ECS behaviour without any faults present. In this experiment the mix valve stayed in the fully cold position (i.e. the hot stream of the mix valve was closed) during the test, forcing the system to cool down all the air coming from the bleed air system. The bypass valve position was modified during testing with three positions selected for model calibration (open, half-open, and closed) and another 3 positions used for model validation. The calibration run results are shown in Figure 5 and they are consistent with the h-s diagram shown in Figure 2.

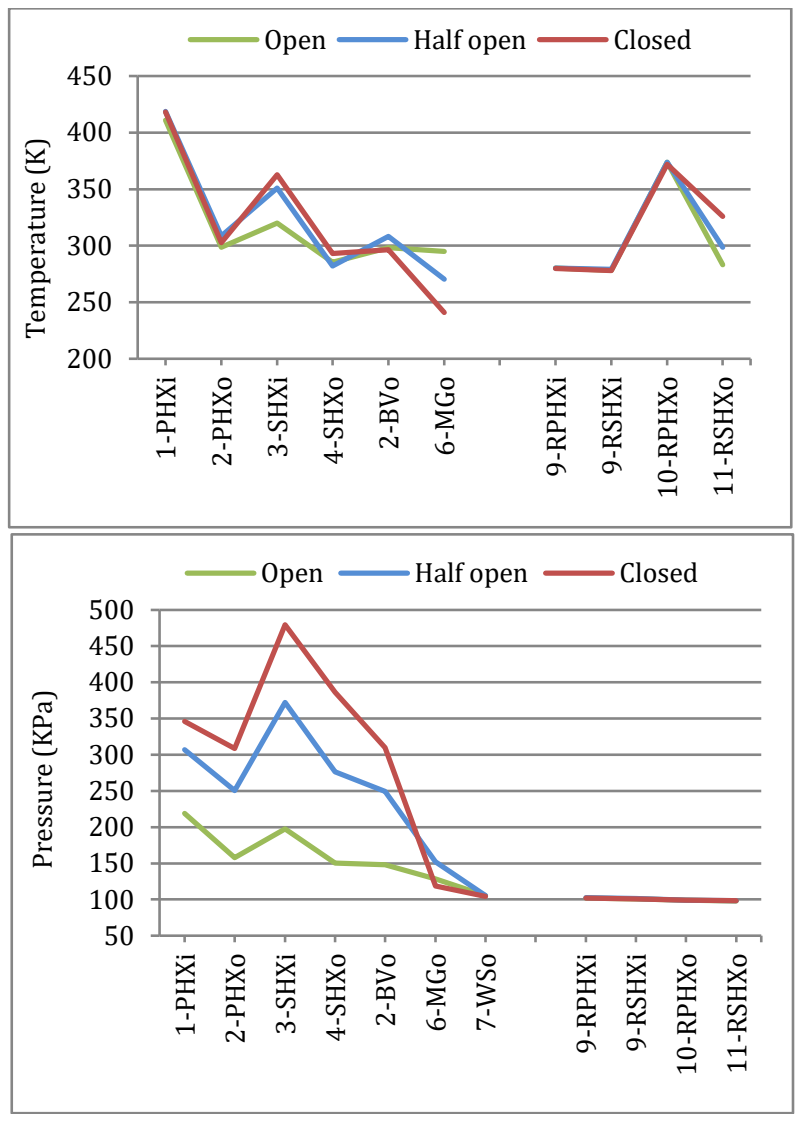

Figure 5 Experimental temperatures (top) and pressures (bottom) throughout a B737-200 ECS, engine at full power with different Bypass Valve positions

As explained before, the bypass valve controls the flow around the ACM, its function being to keep the WS inlet temperature above freezing. The fully closed position represents the coldest delivery and is accompanied by the largest variation in pressure, as the ACM has to perform work on the maximum flow of all cases. Conversely, the fully open position means the temperature of the air hardly changes after the primary heat exchanger, and the pressure drop is the minimum of the 3 cases as the ACM is being bypassed.

The temperature of the ram flow responds to the demands of the heat exchangers. Exit temperature is highest for the closed position of the bypass valve when the secondary heat exchanger is working its hardest. Pressure drop is just due to the friction through the system.

\subsection{Tests with fault injection}

The aim of running tests with fault injections was to collect data to validate the ECS model for certain fault scenarios. The experiments were designed to simulate three of the most common types of faults in ECS: heat exchanger blockage, bypass valve sticking (fully open or fully closed), and water separator clogging. Boundary conditions during the tests are the same as when the system runs at healthy conditions and remain constant once the system reaches the steady state. The procedure to inject each of these faults was:

- Heat Exchanger Blockage: Both heat exchangers were blocked by means of using aluminium plates on the ram air conduit.

- $\quad$ Bypass Valve stuck: The valve was manually operated outside of its normal operating region by using a potentiometer. Two extreme cases have been tested: fully open and fully closed.

- Clogged Water Separator: The water separator has an internal valve that allows air to pass through the water separator to the distribution system without first passing through the coalescer bag. This fault has been triggered by clogging the coalescer bag without exceeding the pressure differential that activates this valve action.

Tests for heat exchanger blockage were conducted with multiple degrees of severity and with different combinations for primary and secondary heat exchangers, resulting in a total of ten failure scenarios. An overview of the experiments is given in Table 1.

\begin{tabular}{|c|c|}
\hline NC & Normal Configuration-Healthy Conditions \\
\hline FM1 & Primary Heat Exchanger Blocked \\
\hline FM2 & Bypass Valve-Open \\
\hline FM3 & Bypass Valve-Closed \\
\hline FM4 & Clogged Water Separator \\
\hline
\end{tabular}

Table 1 Nomenclature for the set of experiments

\section{THERMODYNAMIC MODEL}

The purpose of the thermodynamic model is to simulate how the degradation of individual components produce changes in temperature, pressure, and humidity at different points in the system. The equations used to model the ECS have been selected according to the following assumptions:

- Air with water vapour, or moist air, is considered an ideal gas with a constant specific heat for each species. 
- The ACM housing, pipelines, water separator and mixing section are considered adiabatic, i.e. there is no heat exchange between the working fluid and the outside environment.

- Any mixing process takes place steadily, so kinetic and potential energy changes are considered negligible.

- The pack valve is always open, the mix valve is at the Full Cold position and the bypass valve can change its position.

- Both heat exchangers have the same size and, since they are located in parallel within the ram air conduit, temperature, pressure, and mass flow of the ram air can be considered identical for both heat exchangers

- Condensation before the turbine is extremely unlikely given the high temperature of the bleed air, meaning that $\mathrm{Cp}$ can be considered equal for both hot and cold streams of both heat exchangers.

\subsection{Equations for ECS thermodynamic model}

Both input parameters and thermodynamic properties throughout the ECS have been divided into two streams: the main stream to be conditioned (bleed air) and the one used for heat extraction (ram air). The equations used to calculate changes in temperature and pressure are summarised in Table 2 and they correspond to the same ECS locations shown in Figure 2.
Some model parameters are mass flow dependent (e.g. heat exchanger effectiveness or turbine pressure ratios) but mass flows were not measured during the experiments. This affects the modelling approach in two ways. First, the model must use specific variables. Second, as the bypass valve changes position so does the mass flow (see Figure 6), which modifies the operating conditions of heat exchangers, compressor, and turbine; and the proportion of cold and hot air flow mixed at the turbine outlet. This problem has been addressed by correlating the value of some thermodynamic parameters with the position of the bypass valve, $x$, using the quadratic equation:

$$
\text { Param }=a x^{2}+b x+c
$$

where $a, b$, and $c$ are adjusted using experimental data from a healthy ECS.

The parameters correlated to the bypass valve position using an empirical equation are:

- Primary and secondary heat exchanger effectiveness $\left(\varepsilon_{p h x}, \varepsilon_{s h x}\right)$

- $\quad$ Primary and secondary heat exchanger heat capacity $\left(K_{p}\right.$, $\left.K_{S}\right)$

- Compressor and turbine isentropic efficiencies $\left(\eta_{c}, \eta_{t}\right)$

- Compressor and turbine isentropic pressure ratios $\left(P R_{c}, P R_{t}\right)$

\begin{tabular}{|c|c|c|c|}
\hline \multicolumn{4}{|c|}{ Inputs } \\
\hline \multicolumn{2}{|c|}{$\begin{array}{l}\text { Atmospheric conditions } \\
\text { (Ram Air) }\end{array}$} & $T_{9}=T_{a m b}(K) \quad P_{9}=P_{a m b}(P a)$ & $R H_{a m b}(\%)$ \\
\hline \multicolumn{2}{|c|}{$\begin{array}{c}\text { ECS boundary conditions } \\
\text { (Bleed Air) }\end{array}$} & $T_{1}(K)$ & $x(\%)$ \\
\hline Points & Bleed Air & Temperature $(\mathrm{K})$ & Pressure $(\mathrm{Pa})$ \\
\hline 1 & PV & $T_{1}$ & $P_{1}$ \\
\hline $1-2$ & PHX & $T_{2}=T_{1}-\varepsilon_{p h x}\left(T_{1}-T_{a m b}\right)$ & $P_{2}=P_{1} \cdot Z_{p}$ \\
\hline $2-3$ & ACM-C & $T_{3}=T_{2}\left\{1+\frac{1}{\eta_{c}}\left[\left(P R_{c}\right)^{\frac{\gamma-1}{\gamma}}-1\right]\right\}$ & $P_{3}=P_{2} \cdot P R_{c}$ \\
\hline $3-4$ & SHX & $T_{4}=T_{3}-\varepsilon_{s h x}\left(T_{3}-T_{a m b}\right)$ & $P_{4}=P_{3} \cdot Z_{s}$ \\
\hline $4-5$ & ACM-T & $T_{5}=T_{4}\left\{1-\eta_{t}\left[1-\left(\frac{1}{P R_{t}}\right)^{\frac{\gamma-1}{\gamma}}\right]\right\}$ & $P_{5}=P_{4} / P R_{t}$ \\
\hline $5-6$ & MERGE & $h_{6}=h_{5}+h_{2}$ & $P_{6}=P_{5}$ \\
\hline $6-7$ & WS & $T_{6} \approx T_{7}$ & $P_{7}=P_{6} \cdot Z_{w s}$ \\
\hline $7-8$ & $\mathrm{CV}$ & $h_{8}=h_{7}+h_{1}$ & $P_{8}$ \\
\hline Points & Ram Air & Temperature $(\mathrm{K})$ & Pressure $(\mathrm{Pa})$ \\
\hline $9-10$ & RPHX & $T_{10}=T_{9}+K_{p}\left(T_{1}-T_{2}\right)$ & $P_{10}=P_{9} \cdot Z_{r p}$ \\
\hline $9-11$ & RSHX & $T_{11}=T_{9}+K_{S}\left(T_{3}-T_{4}\right)$ & $P_{11}=P_{9} \cdot Z_{r s}$ \\
\hline
\end{tabular}

Table 2 Key equations of the B737-200 ECS thermodynamic model 


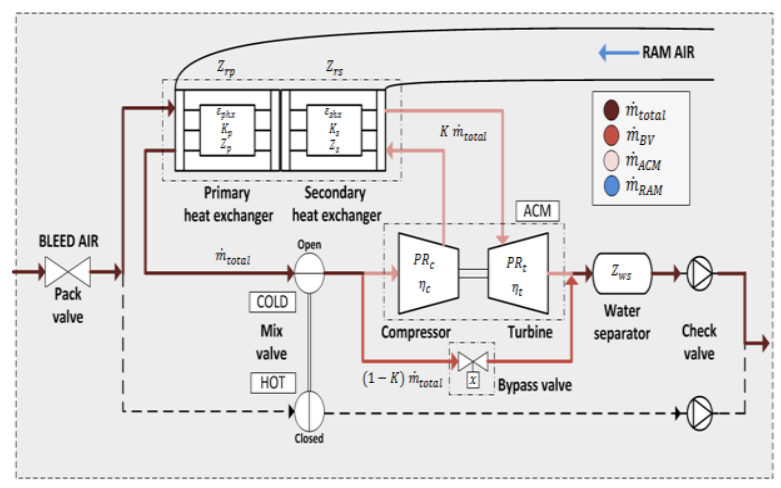

Figure 6 Air mass flow through a B737-200 ECS

- Main stream (bleed air) pressure loss factors through the heat exchangers and water separator $\left(Z_{p}, Z_{s}, Z_{w s}\right)$. It is important to highlight that for the ram air side of the heat exchangers pressure loss factors $\left(Z_{r p}, Z_{r s}\right)$ have been defined as constant values

- The ratio of cold mass flow to total flow at the outlet of the turbine, also called the split ratio ( $K=\dot{m}_{A C M}$ / $\dot{m}_{\text {total }}$ )

\subsubsection{Humidity}

Humidity plays a major effect on the enthalpy of the air stream. Humidity variations are simulated by calculating the specific humidity $(\mathrm{SH})$ at each point, as summarized below:

$$
\begin{gathered}
S H=\frac{m_{v}}{m_{a}}=\frac{0.622 P_{v}}{P_{a}-P_{v}} \\
\frac{R_{a}}{R_{v}}=0.622 \\
S H S=\frac{0.622 P_{v s}}{P_{a}-P_{v S}} \\
R H(\%)=\frac{S H}{S H S} \cdot 100
\end{gathered}
$$

The vapour pressure at saturation $\left(P_{v S}\right)$ is calculated using an empirical expression known as the Tetens equation (Tetens, 1930):

$$
P_{v S}=610.78 e^{17.2694\left(\frac{T-273.15}{T-35.02}\right)}
$$

and if condensation occurs $(S H>S H S)$, the model updates the temperatures taking into account the phase change process. The water vapour that condenses is computed as free moisture $(\mathrm{CO})$ and it is calculated as follows:

$$
\mathrm{CO}=\mathrm{SH}-\mathrm{SHS}
$$

The set of equations given in this section are solved sequentially, starting from point 1 and ending at 11, once the user has provided all the inputs indicated in Table 2 . However, if condensation occurs, the temperatures are updated as necessary in order to take into account the phase change phenomenon described above.

The model can simulate free moisture extraction at point 7 by means of using a water removal efficiency $\left(\eta_{w s}\right)$.

$$
\mathrm{CO}_{7}=\mathrm{CO}_{6} \cdot \eta_{w s}
$$

\subsubsection{Merges}

The mixture properties at the outlet of the merge (MERGE) and check valves $(\mathrm{CV})$, points 6 and 8 , are calculated by means of an energy, mass and humidity balance (see example for point 6 in Table 3). Note that when streams merge the pressure values have to be identical, so the pressure from both check valves is the same, as is the pressure from the bypass valve and the turbine exit. This avoids the need to calculate the pressure drop across these valves.

\subsection{Fault injection in thermodynamic model}

Heat Exchanger Blockage: Heat exchanger blockage is simulated by means of decreasing effectiveness $\left(\varepsilon_{p h x}, \varepsilon_{s h x}\right)$ and increasing heat capacity $\left(K_{p}, K_{s}\right)$ and pressure loss factor $\left(Z_{p}, Z_{s}\right)$. When the cold side of a heat exchanger gets blocked there is less total effective area on that side, diminishing not only the heat transfer capacity of the heat exchanger but also the amount of cold mass flow rate that goes through it.

Valve sticking: Valve malfunction can be due to several causes (e.g. wear, corrosion) but the result is always an undesired position that does not correspond with the expected one. Thus the way of simulating this failure is just by modifying the valve position which has an effect on the split ratio $(K)$

Clogged Water Separator: Water separator clogging not only affects the capacity of this component to remove moisture from the air by reducing its water extraction efficiency $\left(\eta_{\mathrm{ws}}\right)$ but also increases the pressure losses through it $\left(\mathrm{Z}_{\mathrm{ws}}\right)$.

\begin{tabular}{|l|l|l|}
\hline Balances & Equations & Variables \\
\hline Energy & $h_{6}=\frac{C_{p a} T_{6}+S H_{6}\left(C_{p v} T_{6}+H_{f g}\right)+C O_{6}\left(C_{p w} T_{6}\right)}{\left(1+S H_{6}+C O_{6}\right)}=h_{5}+h_{2}$ & Specific enthalpy \\
Mass & $\dot{m}_{6}=\dot{m}_{5}+\dot{m}_{2}=K \dot{m}_{6}+(1-K) \dot{m}_{6}$ & Mass flow rate \\
Humidity & $S H_{6}=S H_{5}+S H_{2}=K S H_{6}+(1-K) S H_{6}$ & Specific humidity \\
\hline
\end{tabular}

Table 3 Thermodynamic equations for energy, mass, and humidity balance at the merge point (6) 
The model simulates the effect of degradation by changing the values of the parameters mentioned above. This is done by multiplying the original value to increase it or reduce it as necessary. For example, a reduction of $20 \%$ in effectives of the primary heat exchanger is introduced in the model by multiplying the value of $\varepsilon_{p h x}$ for healthy conditions by $n_{\varepsilon}=$ 0.8 . This has been found to be a simple but effective way of expressing degradation for users of the simulation.

\section{MODEL CALibRation}

The thermodynamic equations can only be solved once thermodynamic parameters have been specified. Parameters are divided into three groups: i) air properties, ii) fixed pressure loss factors, and iii) quadratic equation parameters for correlation with the bypass valve position. The first group includes dry air properties as well as water vapour and liquid water properties to model the effect of moisture and condensation (see Table 4). The second and third group (Table 5 and Table 6 respectively) are derived from experimental data.

\begin{tabular}{|c|c|}
\hline$R_{a}(\mathrm{~J} / \mathrm{K} \mathrm{kg})$ & 287 \\
\hline$C_{p a}(\mathrm{~J} / \mathrm{K} \mathrm{kg})$ & 1000 \\
\hline$C_{p v}(\mathrm{~J} / \mathrm{K} \mathrm{kg})$ & 714 \\
\hline$C_{p w}(J / K \mathrm{~kg})$ & 4187 \\
\hline$H_{f g}(\mathrm{~J} / \mathrm{kg})$ & 2500 \\
\hline$\gamma(-)$ & 1.4 \\
\hline
\end{tabular}

Table 4 Air Properties

\begin{tabular}{|c|c|}
\hline$Z_{r p}(-)$ & 0.97278 \\
\hline$Z_{r s}(-)$ & 0.97361 \\
\hline
\end{tabular}

Table 5 Pressure Loss factors

\begin{tabular}{|c|c|c|c|c|c|c|}
\cline { 2 - 7 } \multicolumn{1}{c|}{} & $\varepsilon_{p h x}$ & $\varepsilon_{\operatorname{shx}}$ & $K_{p}$ & $K_{s}$ & $Z_{p}$ & $Z_{s}$ \\
\hline$a(-)$ & $2 \mathrm{E}-05$ & $-3 \mathrm{E}-05$ & $-7 \mathrm{E}-06$ & $-5 \mathrm{E}-05$ & $-2 \mathrm{E}-06$ & $3 \mathrm{E}-05$ \\
\hline$b(-)$ & $-5 \mathrm{E}-04$ & $1.6 \mathrm{E}-03$ & $3 \mathrm{E}-05$ & $1.7 \mathrm{E}-03$ & $-1.8 \mathrm{E}-03$ & $-2.9 \mathrm{E}-03$ \\
\hline$c(-)$ & 0.793 & 0.9302 & 0.8744 & 0.3428 & 0.8916 & 0.8051 \\
\hline
\end{tabular}

\begin{tabular}{|c|c|c|c|c|c|c|}
\cline { 2 - 7 } \multicolumn{1}{c|}{} & $\eta_{t}$ & $\eta_{c}$ & $P R_{c}$ & $P R_{t}$ & $Z_{w s}$ & $K$ \\
\hline$a(-)$ & $2 \mathrm{E}-06$ & $-3 \mathrm{E}-05$ & $-5 \mathrm{E}-05$ & $5 \mathrm{E}-06$ & $1 \mathrm{E}-05$ & $-5 \mathrm{E}-05$ \\
\hline$b(-)$ & $-1.7 \mathrm{E}-03$ & $3.5 \mathrm{E}-03$ & $7 \mathrm{E}-04$ & $-1.54 \mathrm{E}-02$ & $7 \mathrm{E}-04$ & $-4.5 \mathrm{E}-03$ \\
\hline$c(-)$ & 0.5517 & 0.8177 & 1.546 & 2.4263 & 0.6516 & 0.9526 \\
\hline
\end{tabular}

Table 6 Parameters modelled with respect to the Bypass Valve position

Pressure loss factors for the ram air side of the heat exchangers $\left(Z_{r p}, Z_{r s}\right)$ have been calculated by measuring the total pressure drop between the inlet and the outlet of these components. These parameters not only depend on the component geometric characteristic but also on the flow properties. As neither of these dependencies is known, an average value for each pressure loss factor was calculated by running the model and comparing to the experimental data points.

As explained previously, ACM, water separator and heat exchanger characteristics (e.g. performance maps, geometry) are unknown, leading to the need for empirical parabolic relationships with the bypass valve angle. The calibration of the model involved adjusting the parameters of each quadratic equation to data collected with the ECS running with the bypass valve open, half-open and closed.

The top diagram in Figure 7 illustrates the decrease in pressure ratios in the ACM as the mass flow through turbine and compressor decrease, with the turbine being more sensitive to the changes of bypass valve position. Similarly, the bottom diagram in Figure 7 shows how the heat capacity of the secondary heat exchanger is more sensitive than for the primary, probably due to the lower temperature difference between bleed and ram air.

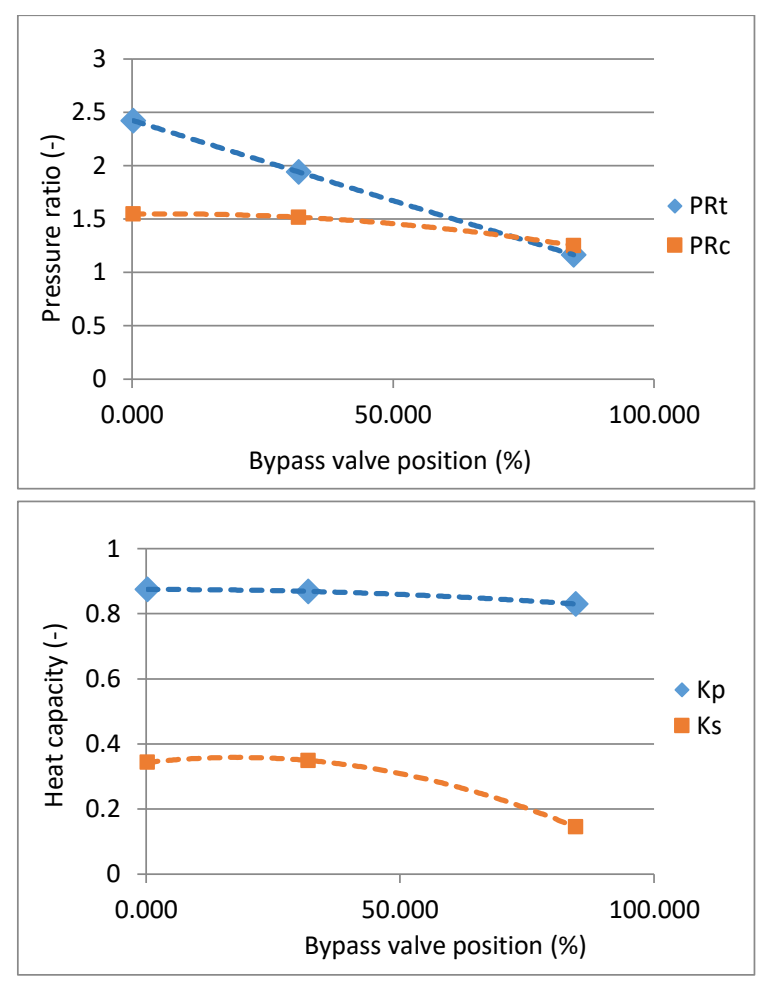

Figure 7 Variation of ACM Pressure Ratios and Heat Exchanger Heat Capacities with bypass valve position

The results of calibrating the simulation are shown in Figure 8. Here, the highest deviation between experimental and simulation results corresponds to the case with the bypass valve in the intermediate position. Nevertheless, maximum errors for temperature and pressures are in the region of $0.5 \%$, with average error less than $0.3 \%$, which is within the error margin of the instrumentation.

This is not surprising given that the data used in this comparison were the same that were used for calibration and 
therefore this is not a good way of assessing the accuracy of the model (remember that the validation was done using a different dataset and it will be discussed in more detail in the next section). However, what this comparison shows is to what extent averaging pressure loss factors and using standard air properties contributes to model error. This is because there cannot be interpolation error for parameters approximated to quadratic equations since we are using experimental points on the curve.

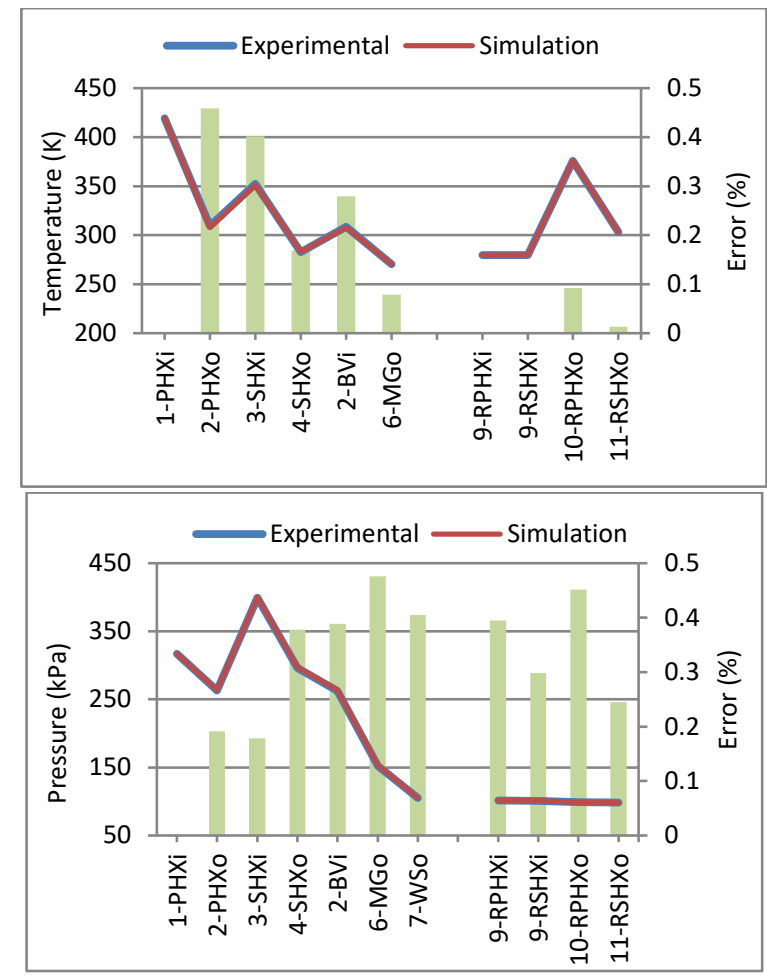

Figure 8 Comparison of temperatures and pressures between experimental data used for calibration and the results of simulations with the bypass valve half open (green bars indicate error level).

\section{VALIDATION}

With the calibration of the model completed, using data collected on a healthy ECS, the next step is to validate the model. The validation is carried out in two stages. First, the model is validated using 3 new experimental data sets collected from a healthy ECS. This provides evidence on the accuracy of the model and its ability to simulate the operation of an ECS with healthy components. Once this stage was completed, the model was validated against experimental data with seeded faults.

\subsection{Validation with healthy ECS data}

Having calibrated the thermodynamic model with real data, this section describes the result of testing the resulting model against 3 new healthy experimental cases. The inputs necessary to run the model are the boundary conditions (i.e. bleed air supply, ECS outlet, and ram air) and the position of the bypass valve. The values for each case are shown in Table 7.

\begin{tabular}{|c|c|c|c|}
\hline Bleed Air & Case 1 & Case 2 & Case 3 \\
\hline$T_{1}(K)$ & 419.2 & 419.2 & 419.2 \\
\hline$P_{1}(P a)$ & 330231 & 343848 & 346261 \\
\hline$P_{8}(P a)$ & 99480 & 99894 & 100083 \\
\hline$x($ deg $)$ & 24.25 & 10.51 & 5.49 \\
\hline Ram Air & Case 1 & Case 2 & Case 3 \\
\hline$T_{9}(K)$ & \multicolumn{3}{|c|}{279.5} \\
\hline$P_{a m b}(P a)$ & \multicolumn{3}{|c|}{52} \\
\hline$R H_{a m b}(\%)$ & \multicolumn{3}{|c}{} \\
\hline
\end{tabular}

Table 7 Model Inputs for Validation

Figure 9 shows a comparison of temperatures and pressures at key points of the ECS with the corresponding deviation for each point.

While the results are consistent across the three cases, the overall temperature error is slightly higher than in the calibration case, with the merge outlet dominating the temperature errors. This may be because the temperature sensor is located close to a point where two streams at different temperatures mix. The temperature distribution is very likely to be non-uniform across the duct (see Figure 4). The model assumes a complete mixing of the flows; the sensor is reading a local value on the periphery of the pipe.

The temperature error for inlet and outlet of the compressor and the inlet of the turbine decrease. This means that errors in the aproximation of pressure ratios and efficiencies are of a different sign to those caused by aproximtions in gas properties and pressure loss factors, compensating one another.

The ram air inlet temperature was measured during the test runs and was found to differ from the ambient temperature. This was thought to be due to the heat exchangers warming up the inlet air since the sensors were very close to the heat exchangers at this location. This does not represent a problem for the model since it does not rely on ambient temperature and it uses the ram air inlet temperature in its equations.

For the pressure readings, errors are higher than in the calibration case. The increase is more noticeable on the bleed air side, which is understandable given that modelling the ram air requries fewer equations and variables and therefore is less prone to the accumulative effect of approximations and errors.

It is worth noting that the maximum increase in pressure error when compared to the calibration case is found on the pressure at the inlet and outlet of the secondary heat exchanger. As the pressure at the outlet of the secondary heat exchanger is governed by the turbine this indicates that the error is caused by the approximation of turbine parameters using quadratic formulae. This can have a cascading effect on 
CASE 1
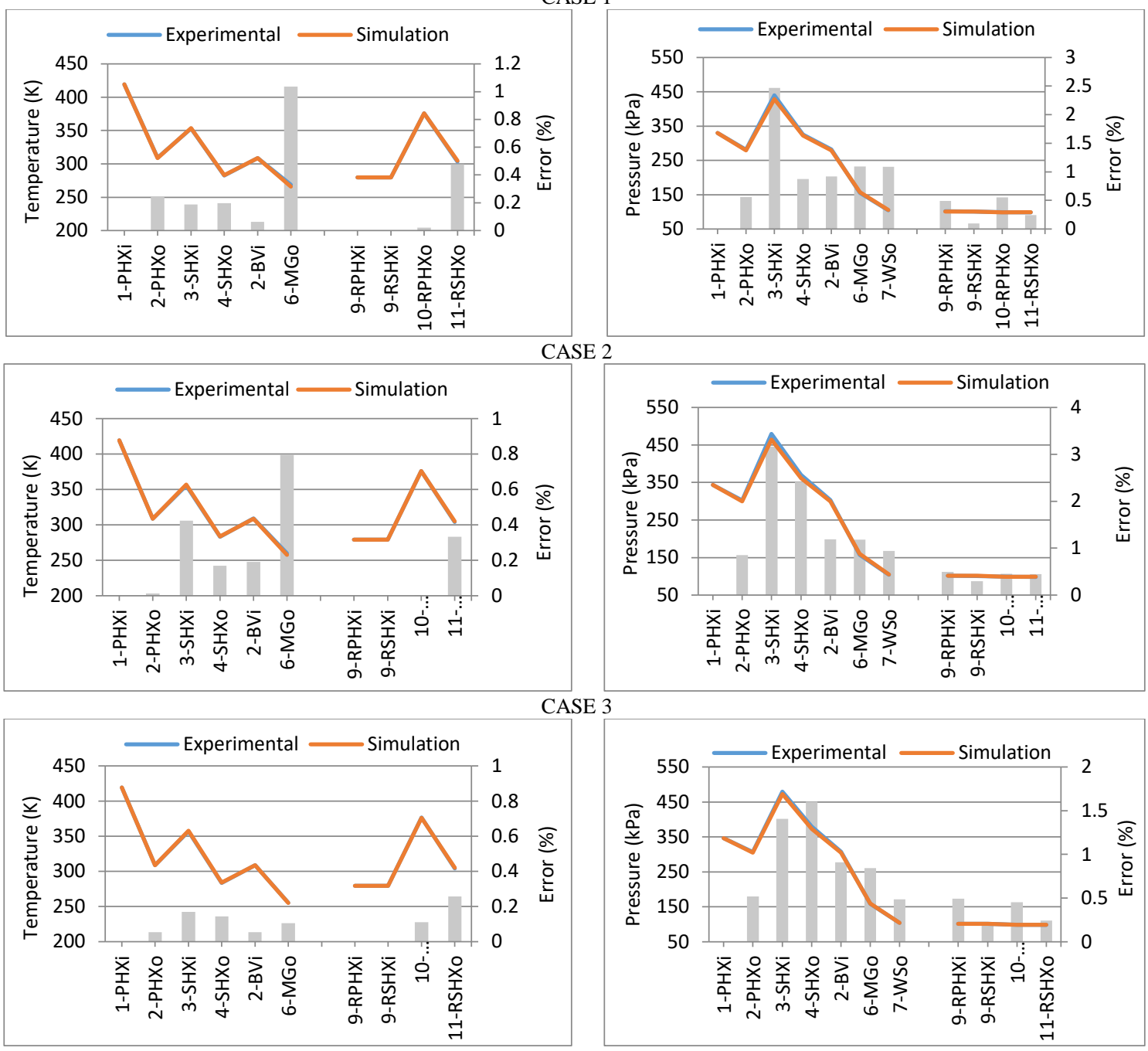

Figure 9 Comparison between experimental data and the results of simulations for the 3 cases selected for the validation of the model (grey bars show error levels).

the error of the pressure inlet of the primary heat exchanger, which explains the increase in its deviation from experimental data. However, this should spread upstream. The fact that the error drops for the inlet and outlet of the primary heat exchanger would indicate that there is also a deviation in the pressure ratio of the compressor that compensates for the original error of the turbine. This is rational as the equations impose an energy balance in the $\mathrm{ACM}$ and any deviation in the pressure ratio of the turbine must be reflected in a deviation on the pressure ratio of the compressor.

The validation above shows that the model can correctly calculate the temperature and pressure profiles of an ECS with maximum deviations of $1 \%$ and $3 \%$ respectively. Based on these results the thermodynamic model is judged to be useful for engineering purposes.

\begin{tabular}{|c|c|c|c|c|}
\cline { 2 - 5 } \multicolumn{1}{c|}{} & FM1 & FM2 & FM3 & FM4 \\
\hline$n_{\varepsilon_{p}}-$ effectiveness of prim heat ex. & 0.41 & 1.00 & 1.00 & 1.00 \\
\hline$n_{K_{p}}-$ heat capacity of prim. heat ex & 2.82 & 1.00 & 1.00 & 1.00 \\
\hline$n_{Z_{r p}}-$ press. loss factor of prim. heat ex. & 0.99 & 1.00 & 1.00 & 1.00 \\
\hline$n_{\varepsilon_{s}}-$ effectiveness of sec. heat ex. & 1.00 & 1.00 & 1.00 & 1.00 \\
\hline$n_{K_{S}}-$ heat capacity of sec. heat ex & 1.30 & 1.00 & 1.00 & 1.00 \\
\hline$n_{Z_{r s}}-$ press. loss factor of sec. heat ex. & 1.00 & 1.00 & 1.00 & 1.00 \\
\hline x: Bypass Valve position. & 35.70 & 85.06 & 0.00 & 42.02 \\
\hline$n_{Z_{w s}}-$ press. loss factor of water sep & 1.00 & 1.00 & 1.00 & 0.92 \\
\hline
\end{tabular}

Table 8 Model parameter multipliers to simulate the faults injected during the seeded fault tests. Values highlighted in green were not altered ( 1 is healthy). 
FM1 - Primary Heat Exchanger Blocked
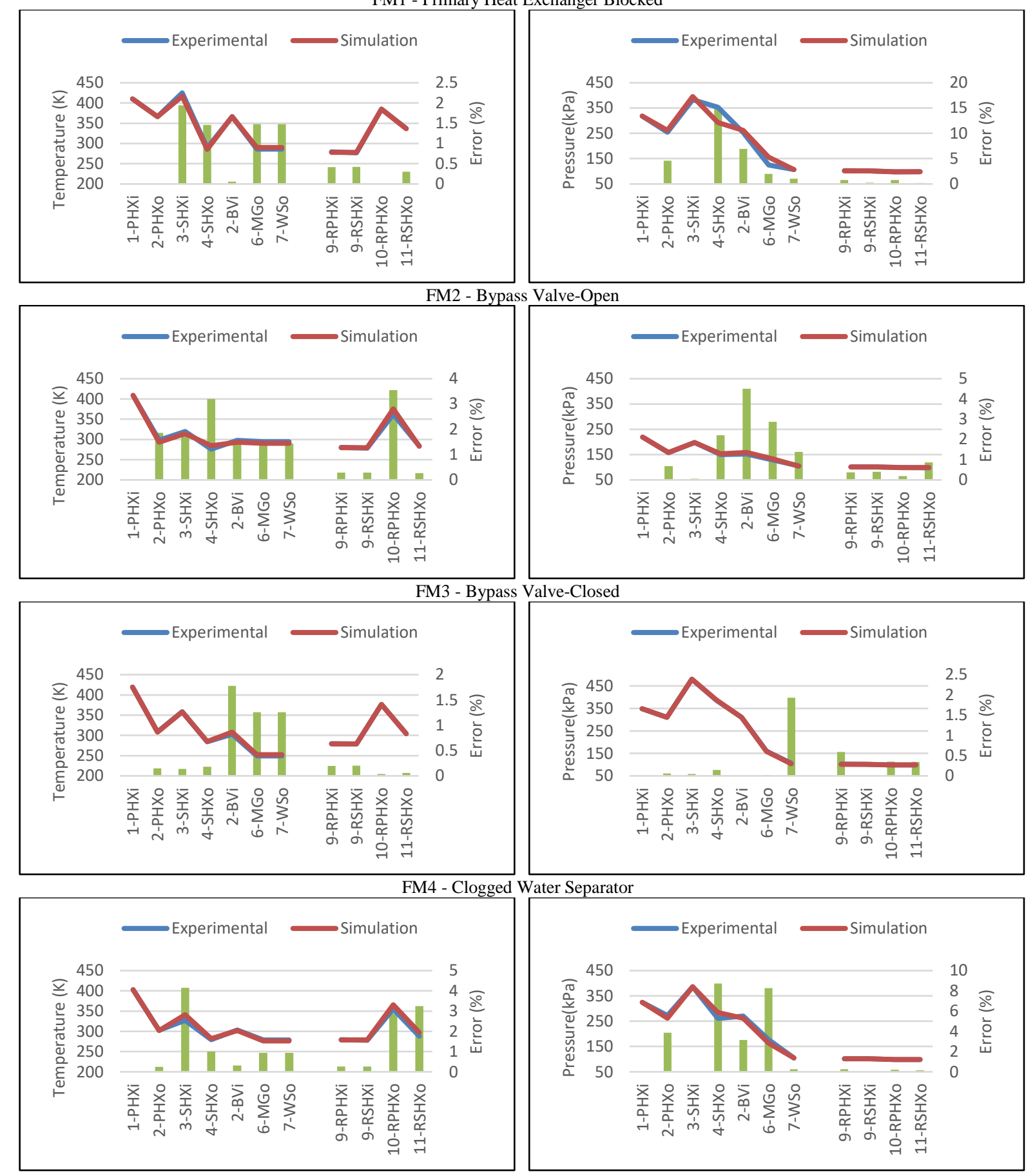

Figure 10 Comparison between thermodynamic model results and experimental data collected for failures modes 1 to 4 .

\subsection{Validation with faulty ECS data}

After the validation of the model for healthy conditions was completed, the model was run to simulate the same faults as those tested in the B737-200 ECS (see Table 1). The values of the parameters of the model were the same as those defined as a result of the calibration, with the exception of those that had to be altered to inject faults in the model. These parameters were described in section 5.2 and Table 8 shows the multiplier applied to each parameter for the FMs investigated.

The results of running the model in these conditions and comparing it to experimental data (Figure 10) shows an increase in model error for both temperatures and pressures when compared to the accuracy of the model for healthy 
conditions. It is also worth noting that the deviation is significantly higher for pressures, particularly for the different cases of heat exchanger blockage, which is consistent with the validation for the healthy case. The objective of this model is to understand how faults present symptoms that can be measured and to use it as the basis to develop diagnostic rules. With this in mind, the temperature error remains low with errors similar to those found in the validation of the healthy case. The maximum deviation reaches $4 \%$, but the average remains around $1.5 \%$ for bleed air temperatures.

It is clear that the values for the ram air temperatures have higher accuracy. This can be explained by the fewer number of counteracting effects on the ram side (e.g. there is no compression and expansion) making it easier to adjust parameters to match experimental data.

The points of maximum temperature error are different for each failure mode and there is no discernible pattern. This means that it is unlikely that there is a single cause for the error in temperatures.

When it comes to the high errors in pressures for primary heat exchanger blockage (FM1), such a significant deviation in the pressure drop across the secondary heat exchanger cannot be explained solely by an error in the approximation of the pressure loss factor because the error diminishes dramatically when the bypass valve was fully open or fully closed (FM2 and FM3 respectively). If the drop of pressure factor was the cause there should be a correlation between drop of pressure error and flow speed. The interaction of the ECS with other systems cannot be discarded.

Pressure errors FM2 and FM3 have the same magnitude as the error for healthy conditions. This is not surprising since these two cases correspond to two extreme bypass valve positions which coincide with two of the points used to calibrate the model. This shows that the increase in error of the model for faulty conditions is most likely caused by deviations between the interpolated quadratic curves and the real values of the parameters they calculate.

Overall, the validation has shown that the model can track the changes in pressures and temperatures caused by the degradation of multiple components. While the errors in pressures remain high for FM1 and FM4, the fact that the error is known means that the model can be used to develop an understanding of the effect of faults, develop diagnostic rules based on it, and adjust thresholds using more accurate experimental data. The model would also benefit from including components and systems upstream and downstream that may interact with the ECS and cause some the higher errors.

\section{ConClusions}

A thermodynamic model of a B737-200 ECS, taking into account humidity, was developed, calibrated, and validated with experimental data collected on a real aircraft on the ground. Experiments performed on a B737-200 ECS provided an excellent data set, not only to validate a thermodynamic model but also to study the behaviour of the system on the ground under healthy and faulty conditions.

The following conclusions can be drawn from the work conducted:

- A thermodynamic model of an ECS can produce results accurate enough for engineering purposes. This opens up new ways to investigate how an ECS performs under healthy and faulty conditions, since now variations in temperature, specific humidity or pressure, can be observed without the need for more expensive tests.

- Whilst the model has been calibrated and validated using data collected for ground conditions, a model of these characteristics should provide a good starting point for other conditions in the aircraft flight envelope.

- The use of thermodynamic parameters such as heat exchanger effectiveness, or compressor and turbine efficiencies, eliminates the need to know the exact geometry or the performance maps of the constituent components. This approach does incur the cost of obtaining experimental data and processing it for use in the model. The accuracy of the obtained results would seem to warrant the approach.

- The use of parabolic relations between the bypass valve setting and model parameters (e.g. split ratio, effectiveness, etc.) has proved successful. Mass flow rates through the system are not required for this model since the effect of the bypass valve position is simulated using empirical approximations. The ACM performance and pressure losses through main components have also been correlated with the valve position following the same approach. Further testing on other ECS would help to determine the reproducibility of these results for other aircraft models.

Future work should focus on finding the best technical solution to detect and isolate the faults described in this article. This requires identifying the optimal sensor set required to detect and isolate said faults and developing a set of logic rules to inform the maintenance team when a component has reached a critical level of degradation so it can be replaced. This could even be expanded to use the ECS sensors for the detection of faults in peripheral systems.

An alternative to using logic rules for fault detection and isolation is running an optimisation algorithm that minimises the residuals by adjusting the parameters used to inject faults in the model. This approach can potentially track the degradation of multiple components since it does not rely in a predefined set of rules. 


\section{NOMENCLATURE}

Symbols:

$B V:$ Bypass valve

$C O:$ Free moisture

$C_{p}:$ Specific heat

$C V$ : Check valve

$\varepsilon$ : Effectiveness

$\eta$ : Efficiency

$\gamma:$ Specific heat ratio

$h$ : Specific enthalpy

$H_{f g}$ : Latent heat-Phase change

$K:$ Split ratio

$m$ : Mass

$\dot{m}$ : Mass flow rate

$P$ : Pressure

$P H X$ : Primary heat exchanger

$P R$ : Pressure ratio

$R$ : Gas constant

$R H:$ Relative humidity

$R P H X$ : Ram-Primary heat exchanger

$R S H X$ : Ram-Secondary heat exchanger

$S H$ : Specific humidity

$S H S$ : Specific humidity at saturation

$S H X$ : Secondary heat exchanger

$T$ : Temperature

WS: Water separator

$x$ : Bypass valve position

$Z$ : Pressure loss factor

Subscripts:

$a$ : Dry air

$a m b$ : Ambient

$b$ : Bleed air

$c$ : Compressor

i: Inlet

$k$ : Split ratio

o: Outlet

$p$ : Primary heat exchanger

$r$ : Ram air

$r p$ : Ram - Primary heat exchanger

rs: Ram - Secondary heat exchanger

$s$ : Secondary heat exchanger

$t$ : Turbine

$v$ : Water vapour

vs: Water vapour at saturation

$w$ : Free moisture

ws: Water separator

\section{BIBLIOGRAPHY}

Burroughs, D. \& Hammond, A., 1983. Control Analysis and Design Features of EASY5. San Francisco, American Control Conference.

Chen, L., Zhang, Z., Wang, C. \& Yang, C., 2015. Analysis on High-Pressure Water Separator. Procedia Engineering, pp. 558-566.

Chen, X., Yang, S., Sun, X. \& Wang, L., 2015. Research on 1D-2D Co-simulation for Cabin Air Environment Accident. Procedia Engineering, Volume 121, pp. Pages 1983-1989.
Childs, T., Jones, A., Chen, R. \& Murray, A., 2016. A Study into Refrigeration Cycle Working Fluids using an Air Cycle Machine Environmental Control System. s.1., 54th AIAA Aerospace Sciences Meeting.

Conceição, S. T., Zaparoli, E. \& Turcio, H., 2007. Thermodynamic Study of Aircraft Air Conditioning Air Cycle Machine: 3-wheel × 4-wheel. s.1., SAE Brasil 2007 Congress and Exhibit.

Jordan, P. \& Schmitz, G., 2014. A Modelica Library for Scalable Modelling of Aircraft Environmental Control Systems. s.1., Proceedings of the 10th International ModelicaConference.

Junior, J., Andrade, C. \& Zaparoli, E., 2009. Numerical analysis of typical aircraft air conditioning air cycle machines. s.1., 20th Int. Congr. Mech. Eng..

Pérez Grande, I. \& Leo, T., 2002. Optimization of a commercial aircraft environmental control system. Applied Thermal Engineering, Volume 22(17), pp. 1885-1904.

Scholz, D., Muller, C., Giese, T. \& Erdmann, C., 2007. FLECS: Functional Library of the Environmental Control System - A simulation tool for the support of industrial processes.. s.1., 1st International Workshop on Aircraft System Technologies.

Scott, T. \& Davis, G., 1976. Thermodynamics of Air / WaterCycle Air- Conditioning Systems. s.1., International Compressor Engineering Conference .

Tetens, V., 1930. Uber einige meteorologische. Begriffe, Zeitschrift fur Geophysik, Volume 6, pp. 297-309.

Tu, Y. \& Lin, G., 2011. Dynamic Simulation of Aircraft Environmental Control System Based on Flowmaster. Journal of Aircraft, 48(6).

Vargas, J. \& Bejan, A., 2001. Integrative thermodynamic optimization of the environmental control system of an aircraft. International Journal of Heat and Mass Transfer, 44(20), pp. 3907-3917. 